\title{
Algal Photosynthesis as the Primary Driver for a Sustainable Development in Energy, Feed, and Food Production
}

\author{
Ida G. Anemaet • Martijn Bekker • Klaas J. Hellingwerf
}

Received: 26 February 2010 / Accepted: 30 June 2010 /Published online: 20 July 2010

(C) The Author(s) 2010. This article is published with open access at Springerlink.com

\begin{abstract}
High oil prices and global warming that accompany the use of fossil fuels are an incentive to find alternative forms of energy supply. Photosynthetic biofuel production represents one of these since for this, one uses renewable resources. Sunlight is used for the conversion of water and $\mathrm{CO}_{2}$ into biomass. Two strategies are used in parallel: plantbased production via sugar fermentation into ethanol and biodiesel production through transesterification. Both, however, exacerbate other problems, including regional nutrient balancing and the world's food supply, and suffer from the modest efficiency of photosynthesis. Maximizing the efficiency of natural and engineered photosynthesis is therefore of utmost importance. Algal photosynthesis is the system of choice for this particularly for energy applications. Complete conversion of $\mathrm{CO}_{2}$ into biomass is not necessary for this. Innovative methods of synthetic biology allow one to combine photosynthetic and fermentative metabolism via the so-called Photanol approach to form biofuel directly from Calvin cycle intermediates through use of the naturally transformable cyanobacterium Synechocystis sp. PCC 6803. Beyond providing transport energy and chemical feedstocks, photosynthesis will continue to be used for food and feed applications. Also for this application, arguments of efficiency will become more and more important as the size of the world population continues to increase. Photosynthetic cells can be used for food applications in various innovative forms, e.g., as a substitute for the fish proteins in the diet supplied to carnivorous fish or perhaps-after acid
\end{abstract}

I. G. Anemaet • M. Bekker · K. J. Hellingwerf $(\bowtie)$

Molecular Microbial Physiology Group,

Swammerdam Institute for Life Sciences,

University of Amsterdam,

Nieuwe Achtergracht 166,

1018 WV Amsterdam, The Netherlands

e-mail: K.J.Hellingwerf@uva.nl hydrolysis - as a complex, animal-free serum for growth of mammalian cells in vitro.

Keywords Oxygenic photosynthesis - Synechocystis sp. PCC6803 · Biofuel · Energy conversion .

Feed and food applications

\section{Introduction}

In the past few decades mankind's annual global energy consumption has increased up to around 14 Terawatts. This annual consumption is expected to even increase to significantly higher levels because of further economic development of currently underdeveloped nations. Since a large part of this energy is derived from fossil supplies, in particular from crude oil, there is serious concern about current levels of carbon dioxide emission. The atmospheric $\mathrm{CO} 2$ concentration meanwhile already has increased to 384 parts per million (ppm), up from $280 \mathrm{ppm}$ at the start of the Industrial Revolution (Etheridge et al. 1996). In the period between 2000 and 2007, atmospheric CO2 concentration grew by an average of $1.8 \mathrm{ppm}$ per year, the fastest 7-year increase since continuous monitoring began in 1959. This means that by the end of this century, if the current rate of consumption of fossil forms of energy is maintained and if no further action (e. g., via the introduction of the very energy-intensive carbon-capture technology) is taken, $\mathrm{CO}_{2}$ levels will rise to over $550 \mathrm{ppm}$, whereas even higher levels will abound if the world's rate of annual fossil fuel consumption will increase even further. For sure a scenario that causes anxiety indirectly (Smith et al. 2008; Hovatta and Barlow 2008).

The only realistic way of addressing this issue is to find (a combination of) energy sources, which can cope with 
global demand while limiting $\mathrm{CO}_{2}$ emission. There are, unfortunately, very few possibilities to achieve this, particularly with respect to the production of (liquid) transport fuel, whereas for the sustainable production of electricity, various sources can be tapped that do not contribute to increasing $\mathrm{CO}_{2}$ levels like wind and tidal energy and photovoltaics. The only viable option for producing liquid transportation fuel efficiently is through natural photosynthesis. Such fuel products are carbon neutral in the sense that the $\mathrm{CO}_{2}$ burned from any carbonbased fuel generated from products of photosynthesis is never more than that taken up by the plants to grow in the first place. If produced properly, no additional fossil fuel is necessary for the workup of the biofuel (Lynd et al. 2006). The basic advantage of the production of solar biofuel over solar or wind-derived electricity is that biofuels inherently solve the storage problems that have their origin in the absence of high-capacity and cheap storage facilities (i.e., batteries) and/or the - primarily circadian - fluctuation of sunlight intensity.

\section{ABE Fermentation}

Large-scale biofuel production systems already exist. Most of these use the Acetone-Butanol-Ethanol (ABE) fermentation process. In this process polysaccharides/sugars, the primary products of natural photosynthesis, are converted into organic solvents like ethanol, acetone, and butanol by microorganisms like Clostridium acetobutylicum. This process, often referred to as solvatogenesis, was developed about one century ago, initially for the production of synthetic rubber from butanol, soon followed by the production of acetone that was used as the solvent in the production of smokeless gunpowder (Woods 1995). In nature, this process functions not only to provide cells with metabolic energy when oxygen and other external electron acceptors are lacking, but also in the overflow metabolism of aerobes, i.e., when organisms like lactic acid bacteria and yeasts are suddenly confronted with a large excess of sugar (Tempest and Neijssel 1979).

During the past 100 years, the industrial use of the ABE fermentation has seen many ups and downs mostly due to low prices for competing (fossil) fuels. In spite of this, impressive progress has been made regarding metabolic engineering of chemoheterotrophic and fermentative microorganisms such as Escherichia coli (Atsumi et al. 2008), Clostridia (Papoutsakis 2008) and yeasts (Chu and Lee 2007) for the production of these solvents.

\section{Methanogenesis}

Evolution has provided one more metabolic mode to convert substrate into an important biofuel even when all external electron acceptors and fermentable sugars have been exhausted: methanogenesis. In this process, the reducing equivalents of intermediates like acetate and hydrogen are converted into methane, a versatile energy carrier; however, the molecular basis of methanogenesis is very different from most other modes of catabolism (it is e. g., present exclusively in members of the domain of the Archaea) and is very sensitive to even traces of oxygen (Thauer et al. 2008). Therefore, we think that this metabolic pathway does not qualify for the construction of "photofermentative" chimeras (see below, A Photofermentative Chimera). Nevertheless, in an energy-centered economy in which the most efficient use of the products of natural photosynthesis is of key importance, methanogenesis may make an important contribution to the energy budget of bioenergy production systems via fermentation of residues after any biorefinery.

\section{Solar Energy Conversion}

Artificial Versus Natural Photosynthesis

Approximately $5 \mathrm{kWh}$ of solar energy is impinging on every square meter of the earth every day. Already for the land surface area of our planet only, this amounts to $(\sim 3)$ orders of magnitude more than the current rate of energy consumption of the human population. However, because light represents a very distributed (diluted) source of energy it is a challenge to harvest significant amounts of it. Two basically different approaches to convert it into useful forms of energy for mankind compete intensely in the research community, the use of natural and artificial forms of photosynthesis. Natural photosynthesis will be discussed in detail below (see in particular, Three Types of Photosynthesis). Artificial photosynthesis comes in many different forms, of which the most important is the use of solar energy to directly generate electricity through photovoltaics. In this process, the energy of a solar light quantum is used to allow dye-derived electrons to bridge a band gap. Subsequently, these electrons return to their place of origin after passing through an external load. Dependent on the type of (advanced) material used and the details of its principle of operation and construction, the conversion efficiency of photovoltaic devices at the research scale can be as high as $40 \%$, slightly higher than the maximal theoretical efficiency of the primary reactions of natural photosynthesis (see further below). By adjusting the size of the band gap to the wavelengths of the photons available, the efficiency of photovoltaic devices can perhaps even further be increased. Natural photosynthesis, on the other hand, has the key advantage of being auto-regenerative. Successful application of photovoltaic cells therefore 
requires optimization of the triad: (1) efficiency, (2) cost of production, and (3) operational lifetime. This optimization has proceeded to the extent that in several countries this has already led to a significant capacity for the generation of solar electricity (Gratzel 2001).

Another possibility is to convert solar energy directly into heat and, if necessary, next into electricity - in a solar power plant. Both subsequent conversions can be carried out with considerable efficiency (Rolim et al. 2009).

\section{Fuel Versus Electricity Production}

Not every type of fuel is equally suited for all applications. Some forms like electricity and heat, and to a lesser extent molecular hydrogen, suffer from the fact that they cannot easily be transported over long distances as such, unless specific precautions are made like the use of high-capacity (and by necessity, heavy) batteries in the case of electricity. This makes these energy carriers less suited for e.g., the field of aviation and heavy transport. Furthermore, in specific fields like in the chemical industry, fossil fuel is not only used as an energy source, but rather, primarily as the basis for feedstock product formation. Nevertheless, a lifecycle analysis of many products derived from these feedstock products will show that a large fraction of its carbon will finally end up as atmospheric $\mathrm{CO}_{2}$ (be it that another significant fraction will be converted to plastic debris that accumulates in the oceans (Laist 1987)). Therefore, it is to be expected that a significant demand specifically for liquid fuel will persist in our society for the years to come. Biofuels may cover a significant part of this demand in the future.

An important consideration concerning suitable sources to derive this liquid fuel from is the fact that chaining multiple processes rapidly leads to very low overall efficiencies. To give a numerical example, the chaining of four processes, each separately having an efficiency of $33 \%$, gives an overall efficiency of the process of only $1 \%$ ! Hence, in setting up plans for future energy supply, it is important to minimize the subsequent number of energy conversions. This is particularly relevant for plans that contain an electricity-to-fuel conversion because efficient procedures for this step are not (yet) available.

\section{The Biosolar Cell}

Many of the reactions that are catalyzed by the living (phototrophic) organisms can also be accelerated in vitro by (in)organic catalysts. This has led to the concept of the biosolar cell, a catalytic (nano)device that converts $\mathrm{CO}_{2}$ and $\mathrm{H}_{2} \mathrm{O}$, with the use of solar energy, into fuel molecules. The development of such a device, however, still requires a fundamental and technological breakthrough at various levels: First, multi-electron redox catalysts must be devel- oped for the reduction of $\mathrm{CO}_{2}$ and the oxidation of water (Boichenko et al. 2004). These catalysts must then be coupled to each other as well as to efficient light harvesters and photochemical reaction center mimics, in materials with a surface area sufficient to allow rapid access of these substrates (including the photons) and removal of the fuel product. For this, a considerable body of physical and chemical research is required, inspired by biological processes, in research fields like biomimetic nanotechnology.

For the long-term fuel supply, this approach holds specific promises like the use of the complete spectrum of solar radiation with maximal efficiency, but it requires also that the many challenging problems in catalysis, as previously mentioned, be solved.

\section{Photosynthesis and Bioenergy}

\section{Three Types of Photosynthesis}

Photosynthesis is the Earth's most successful solar energy converter. It provides energy for almost all life on our planet and is the source of the fossil fuels that drive our technologies. Evolution in nature has led to the emergence of three basic types of photosynthesis (Fig. 1). In the first two of these, retinal-based photosynthesis and anoxygenic photosynthesis, light merely functions to provide the cell with extra metabolic energy via proton motive force generation and coupled ATP synthesis (Johnson and Schmidt-Dannert 2008). The crucial difference between these first two types are the pigments used: Schiff-base coupled retinaldehyde linked to a lysine of apobacteriorhodopsin as a light-driven proton pump in the former and bacteriochlorophyll and carotenoid-based antennae pigments, and a more restricted number of the same pigments in the reaction centers that jointly drive cyclic electron flow in the latter. A key consequence is that in organisms that use either of these types of photosynthesis, light can only function as an auxiliary energy source and the cells always need an external inorganic or organic electron donor to form biomass from $\mathrm{CO}_{2}$. Although such phototrophic organisms can lower the midpoint potential of the external electron donor via reversed electron flow driven by the proton gradient (Hellingwerf and Konings 1985), the midpoint potential of electrons derived from water is too high to be of any use for such organisms. The principle difference between these two types is that the use of antenna pigments to channel excitation energy to the reaction centers - as a response to the dilute nature of sunlight - is nearly absent in retinal-based photosynthesis. The non-covalently attached salinixanthin to the proteorhodopsin from Salinibacter ruber is so far the only known exception (Balashov and Lanyi 2007). 
a

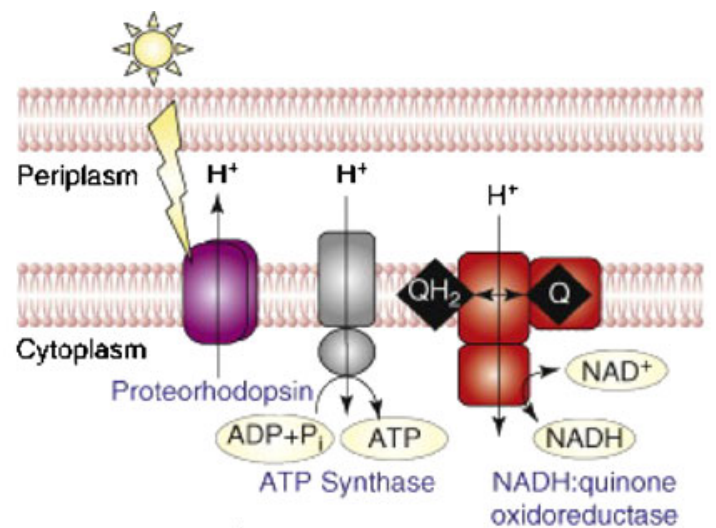

b

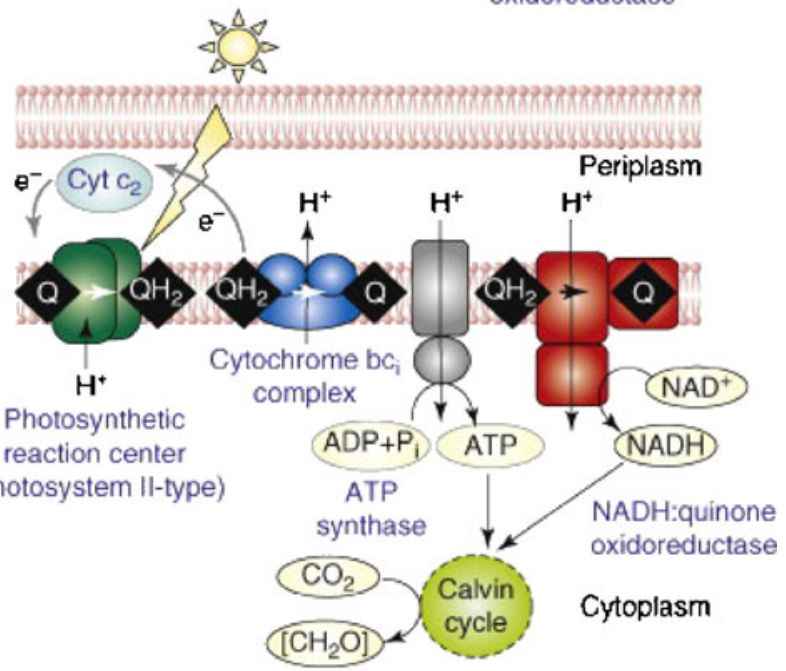

C

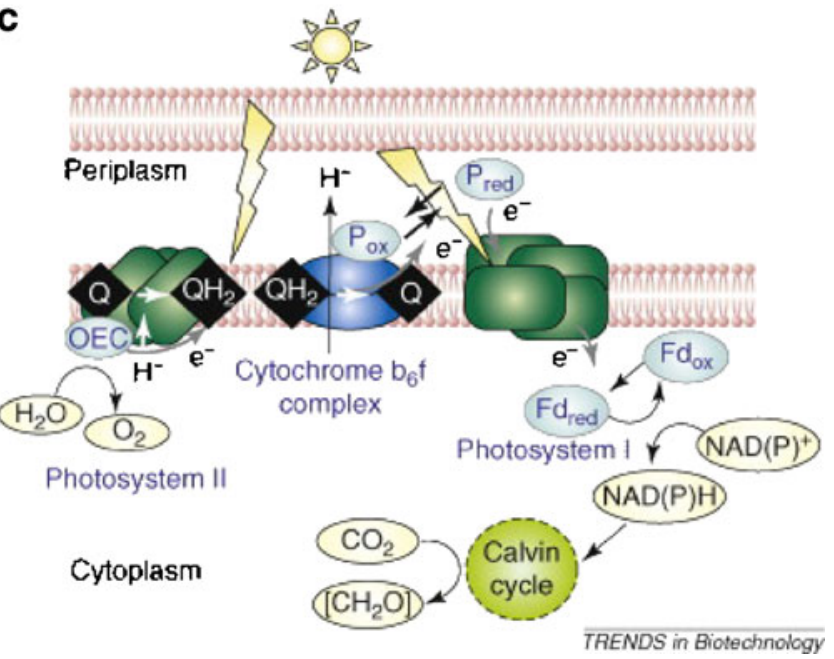

Fig. 1 Illustration of the three basic types of photosynthesis: retinalbased, anoxygenic, and oxygenic photosynthesis in microorganisms. Each panel shows a cross section of the cytoplasmic membrane that defines the periplasm and cytoplasm. Protein components have blue labels; small molecules have black labels. Black and white arrows represent reactions catalyzed by each enzyme. a Light-driven proton pump. b Overview of anoxygenic photosynthesis from Rhodobacter sphaeroides. c Overview of oxygenic photosynthesis from cyanobacteria. (From Johnson and Schmidt-Dannert 2008, with permission)
The third type of photosynthesis is oxygenic photosynthesis. In the organisms that carry out this type of metabolism, i.e., plants, algae and cyanobacteria, the photosystems II and I are coupled in a series to facilitate light-energy input (via extensive sets of antennae) to decrease the midpoint potential of electrons derived from water to the (very negative) redox level of NAD(P)H (Bryant and Frigaard 2006). The two photosystems are coupled via an electron transport chain composed of plastoquinone/ol, the cytochrome $\mathrm{b}_{6} / \mathrm{f}$ complex and plastocyanin or cytochrome $c_{6}$. In parallel to the NADPH, an amount of ATP is formed-through a chemiosmotic mechanism (Blankenship 2002) - that exactly matches the requirements of the Calvin cycle for NADPH and ATP for the conversion of $\mathrm{CO}_{2}$ into precursors for biomass synthesis. Oxygenic photosynthesis additionally forms oxygen as a waste product. Furthermore, it has the key advantage over the other forms of natural photosynthesis that it can tap the electrons - necessary to form biomass from $\mathrm{CO}_{2}$-from the almost unlimited reservoir of water.

Detailed atomic/molecular information is available about the structure of the macromolecular components that make up the electron transfer chain in the thylakoid membranes of oxygenic photosynthesis, including crystal structures of the most important complexes involved (Nelson and Ben-Shem 2004). Likewise, spectroscopic studies have revealed intricate details of their functional aspects related to excitation and electron transfer as well as to chemiosmotic free energy transduction (Blankenship 2002). Through combining this information computational models are being made that may prove useful, e.g., for prediction of photosynthetic performance under light/dark cycling conditions. These models, however, have not yet become as detailed as those for anoxygenic photosynthesis (Geyer and Helms 2006; Geyer et al. 2007) mainly because of uncertainty about the mutual stoichiometry of the functional complexes involved.

\section{Photosynthetic Productivity}

Photosynthesis is a process with large inherent, unavoidable, loss processes (Zhu et al. 2008). The best known of these is the $\sim 40 \%$ energy loss of blue photons absorbed by the chlorophyll-containing antennas because the high amount of energy of photons of blue color excites chlorophyll pigments to a higher excited state, which on the ultra-fast timescale relaxes to the singlet-excited state, thereby converting the excess energy directly into heat. Significantly, many more of such loss processes have been identified, such as: (1) incomplete light absorption by the canopy of a particular crop, (2) non-photochemical quenching ((Muller et al. 2001), particularly relevant at high light intensities), (3) losses in the conversion of $\mathrm{CO}_{2}$, ATP and 
NADPH into sugars, and via (4) photorespiration and (5) respiration. This leads to estimated theoretical yields of biomass synthesis in plants of $4.5 \%$ and $6 \%$ of the incoming radiation energy for $\mathrm{C}_{3}$ and $\mathrm{C}_{4}$-plants, respectively (Zhu et al. 2008).

The actually observed yield of plant biomass in agriculture is several-fold lower. Numbers in the literature generally report a value of $20 \mathrm{t}$ of dry biomass per hectare per year as the maximum (e.g., 4; 25). For moderate latitudes with an annual amount of solar energy available of $\sim 10^{14} \mathrm{~J} / \mathrm{ha}$ [(De Vos and de Mey 1977); assuming 300 days with ten sun hours each and $17 \mathrm{~kJ} / \mathrm{g}$ energy content of the biomass], this equals less than $0.5 \%$ overall energetic efficiency. A multitude of additional factors can further lower agricultural plant biomass yield, such as plants having to maintain large non-productive parts, poor soil quality and/or water availability, presence of insects, etc. This further reduces the efficiency of biomass formation often to less than $20 \%$ of the maximally achievable yields (Boyer 1982; Larcher 2003; Vetter 2005), which translates into a yield of less than $4 \mathrm{t}$ of biomass per hectare per year.

The harvested biomass can be of either one of four basic types (Lynd et al. 2006): (1) lignocellulose-, (2) starch-, (3) sucrose-, or (4) oil-rich biomass. This composition in turn dictates the next most beneficial processing step to derive biofuel from it, which is ethanol fermentation for starchrich biomass and biodiesel production for oil-rich crops. This then may lead to up to between 5,000 and $10,000 \mathrm{~L}$ of biofuel per hectare per year (see Table 1).

Beyond the plants, we find oxygenic photosynthesis in both eukaryotic and prokaryotic algae (or cyanobacteria). In these aquatic microorganisms the efficiency of photosynthesis is appreciably ( tenfold; Usui and Ikenouchi 1997) higher than in plants. For these microorganisms e.g., it is much more straightforward to absorb all incoming radiation. Furthermore, they do not have large non-productive structures to maintain and it is technologically straightforward to allow them to grow under optimal physiological conditions even at moderate to large scale (Posten 2009) at high yields. This is particularly true for the cyanobacteria, presumably in part because they have a tenfold lower maintenance energy requirement than green algae (Gons and Mur 1980). In agreement with this, it has been reported that higher biomass productivity based on oxygenic photosynthesis has been obtained from mass cultures of oxyphototrophic microorganisms like Chlorella (Mandalam and Palsson 1998), and particularly Scenedesmus (Ratchford and Fallowfield 1992) and Spirulina (Jimenez et al. 2003). For moderate-size facilities $\left(>1,000 \mathrm{~m}^{2}\right)$ productivities up to $80 \mathrm{t} / \mathrm{ha} /$ year have been reported and up to $100 \mathrm{t} / \mathrm{ha} /$ year seems to be achievable (Janssen et al. 2000; Janssen et al. 2003). Clear differences in data obtained on the maximally achievable biomass yields with cyanobacteria and (green) algae are not directly apparent from the literature, but this may be related to the current emphasis in basic and in applied research on the large-scale growth of eukaryotic algae for the production of biodiesel.

The amount of biofuel that can be recovered annually per hectare in first- and second-generation biofuel production systems depends on the specific nature of the crop that is used, i.e., whether it is lignin- or triglyceride-rich. Typically, these yields are in the order of between 5,000 and 10,000 L/ha/year (see Table 1) for the primary fuel. Nevertheless, the residue after processing may have an important energetic impact too. For instance, for lignin-rich biomass this implies that this residue can provide most of the process energy for the fuel production (Lynd et al. 2006) making this type of crop relatively efficient in terms of fossil fuel replacement. According to Chisti (2007), however, the use of terrestrial crops for the production of biodiesel cannot compete with that of algae. For instance, from soybean only $450 \mathrm{~L}$ of oil per hectare per year can be produced and to replace $50 \%$ of the needs for transport fuel in the US an area three times the size of the US will be required. Microalgae, in contrast, can produce up to $100,000 \mathrm{~L} / \mathrm{ha} /$ year, depending on their oil content, which can vary between $30 \%$ and $70 \%$ of their dry weight. This oil consists mainly of triglycerides, which can easily be converted into biodiesel. For this approach it would take only between $1 \%$ and $3 \%$ of the existing US crop area to replace half of the petroleum-based transportation fuel with biodiesel.

\section{Current Biofuel Production Technologies}

\section{First-, Second-, and Third-Generation Processes}

The first inklings that one could make methane, lipids and/or hydrogen out of cyanobacterial and algal biomass via direct conversion of the energy from sunlight came up in the early 1950s (Oswald et al. 1953). This led to an initial spur in photosynthesis research in the 1970s (see e.g., Slater 1976), be it in part focused on photovoltaics. During the next decade low oil prices strongly reduced interest in biofuel production until at the turn of the century this trend reversed. This has led to a situation that currently two major technologies use oxyphototrophs to produce biofuel: firstly, plant-based biofuel production via fermentation of cellulosic biomass, and secondly, algae-based biodiesel production via lipid extraction of biomass from large-scale cultures.

First Generation: Plant-Based Ethanol Production

Capturing of solar energy through oxygenic photosynthesis enables plants to store a large part of the absorbed 
Table 1 Comparison of first-, second-, and third-generation strategies for biofuel production

\begin{tabular}{|c|c|c|c|c|c|c|}
\hline Source & Fuel product & $\begin{array}{l}\text { Current yield } \\
\left(\text { ha }^{-1} \text { year }^{-1}\right)\end{array}$ & $\begin{array}{l}\text { Maximal theoretical } \\
\text { yield }\left(\mathrm{ha}^{-1} \text { year }^{-1}\right)\end{array}$ & $\begin{array}{l}\text { Maximal } \\
\text { economic yield } \\
\left(\mathrm{K}_{\epsilon} \mathrm{ha}^{-1} \mathrm{year}^{-1}\right)^{\mathrm{a}}\end{array}$ & $\begin{array}{l}\text { Global demand } \\
\text { per year }\end{array}$ & Reference \\
\hline Sugar cane & Ethanol & $6,000 \mathrm{~L}$ & & & $>>10^{11} \mathrm{~kg}$ & (Chisti 2008) \\
\hline Sugar beet & Ethanol & $7,000 \mathrm{~L}$ & & & $>>10^{11} \mathrm{~kg}$ & (Langeveld et al. 2008) \\
\hline Maize & Ethanol & $3,500 \mathrm{~L}$ & & & $>>10^{11} \mathrm{~kg}$ & (Muller et al. 2008) \\
\hline Palm Oil & Biodiesel & $5,500 \mathrm{~L}$ & & & $>>10^{11} \mathrm{~kg}$ & (Muller et al. 2008) \\
\hline Rapeseed & Biodiesel & $1,200 \mathrm{~L}$ & & & $>>10^{11} \mathrm{~kg}$ & IPTS $^{b}$ \\
\hline Soybean & Biodiesel & $500 \mathrm{~L}$ & & & $>>10^{11} \mathrm{~kg}$ & (Hill et al. 2006) \\
\hline Algae & Biodiesel & & $58,700 \mathrm{~L}$ & & $>>10^{11} \mathrm{~kg}$ & (Chisti 2008) \\
\hline Cyanobacteria & Ethanol & $50,000 \mathrm{~L}^{\mathrm{c}}$ & $168,000 \mathrm{~L}^{\mathrm{c}, \mathrm{d}}$ & $81^{\mathrm{e}}$ & $>>10^{11} \mathrm{~kg}$ & (Angermayr et al. 2009) \\
\hline Cyanobacteria & Ethylene & $336 \mathrm{~kg}$ & $82,000 \mathrm{~kg}^{\mathrm{d}}$ & 92 & $5 \times 10^{10} \mathrm{~kg}$ & $\begin{array}{l}\text { This study, (Takahama et al. } \\
\text { 2003; Meehan 2008) }\end{array}$ \\
\hline Cyanobacteria & Isobutanol & $13,125 \mathrm{~L}$ & $147,000 \mathrm{~L}^{\mathrm{d}}$ & $147^{\mathrm{f}}$ & $4 \times 10^{11} 1^{\mathrm{g}}$ & This study, (Atsumi et al. 2009) \\
\hline Cyanobacteria & Succinate & ND & $259,000 \mathrm{~kg}^{\mathrm{d}}$ & $208-1,527$ & $10^{7} \mathrm{~kg}$ & $\begin{array}{l}\text { This study, (Song and Lee 2006; } \\
\text { van Dongen et al. 2008) }\end{array}$ \\
\hline Cyanobacteria & Acetone & ND & $159,000 \mathrm{~L}^{\mathrm{d}}$ & 106 & NA & This study, (Meehan 2008) \\
\hline Cyanobacteria & Propanol & ND & $150,000 \mathrm{~L}^{\mathrm{d}}$ & NA & NA & This study \\
\hline Cyanobacteria & Isobutyraldehyde & $18,690 \mathrm{~kg}$ & $126,000 \mathrm{~kg}^{\mathrm{d}}$ & NA & NA & This study, (Atsumi et al. 2010) \\
\hline
\end{tabular}

Yields refer to actually achieved production capacity; maximal yield to the theoretical limits

$N D$ not determined, $N A$ no data available

${ }^{\mathrm{a}}$ Costs of downstream processing not included

${ }^{\mathrm{b}}$ IPTS, Techno-economic analysis of Biodiesel production in the EU: a short summary for decision-makers, EUR 20279, 2002

${ }^{\mathrm{c}}$ Data obtained from or confirmed at www.algenol.com

${ }^{\mathrm{d}}$ Based on 3,000 h of sunlight per year, $650 \mu \mathrm{E}$ light and the assumption that all carbon dioxide fixed is converted to product

${ }^{\mathrm{e}}$ Based on recent price of 600 euro $/ \mathrm{m}^{3}$

${ }^{\mathrm{f}}$ Based on a butanol price of 1 euro/L

${ }^{\mathrm{g}}$ Price strongly dependent on total volume of world market for this product

energy in the form of sugars and polysaccharides. These compounds may obtain the form of intracellular sucrose and starch or (extracellular) cell wall polymers composed of cellulose, hemicellulose, and lignin. The first two of these products can straightforwardly be fermented to alcohols like ethanol, propanol, and butanol (Woods 1995). Exploitation of the lignocellulose fraction, however, requires more elaborate processing steps, including heat and acid treatment (Van Wijk 2001; Mosier et al. 2005). It is promising that recently enzymes have been discovered in thermophilic and acidophilic organisms known to degrade lignocellulose such as Caldicellulosiruptor saccharolyticus and Acidothermus cellulolyticus (Viikari et al. 2007) that may accelerate this process. It should be noted, however, that a large part of the remaining plant biomass, after its use for first-generation biofuel production, is still well-suited for the production of food or feed (Marris 2006; Buerkert and Schlecht 2009) or for the production of energy, e.g., through methane fermentation.
A Second-Generation Process: Algae-Based Biodiesel Production

In recent years, microalgae have come into the spotlight of the biofuel research community. This is because several species have been identified that produce lipids (either triglycerides or poly-isoprenoids (Metzger and Largeau 2005; Ratledge 2004) up to very high cellular levels, particularly when cells are starved for nitrogen. If the former type of lipid predominates, biomass fractionation followed by transesterification with methanol, then results in the formation of biodiesel. Both specific plant crops like palm and soy, and selected microorganisms like Botryococcus braunii and Nannochloropsis sp. are well-suited for this approach. The absence of interference with food production and of the use of arable land, meanwhile, has shifted most efforts in biodiesel production towards the microorganisms (Chisti 2007).

Microalgae have therefore been proposed as excellent candidates for fuel production because of their combined 
advantages of high-photosynthetic efficiency, biomass production and faster growth, as compared to other energy crops (Milne et al. 1990; Ginzburg 2003; Dote et al. 1994; Minowa et al. 1995). They may also be better suited for genetic engineering and high-throughput phenotypic analyses (Walker et al. 2005; Elsey et al. 2007; Geng et al. 2003; Tan et al. 2005). Furthermore, as these organisms can grow photoautotrophically, their simple growth requirements make them well-suited for growth in large-scale photobioreactors for the industrial-scale production of biofuel in the twenty first century.

In part of the scientific literature a second-generation biofuel production process is defined differently, that is as a process in which (a part of) the more recalcitrant plant polymers like (ligno)cellulose are converted into ethanol (Galbe and Zacchi 2007).

\section{A Third-Generation Process: The Photanol Approach}

\section{Introduction}

The two above described approaches both have an intrinsic inefficiency. Both the ATP and NADPH synthesized in the thylakoids are converted via the Rubisco enzyme and the rest of the Calvin cycle into $\mathrm{C}(3)$ [and $\mathrm{C}(6)$ ] sugars, which next are the substrate for the complex set of metabolic pathways that jointly form anabolism. The resulting biomass must then be harvested, fractionated, and the relevant fraction processed via fermentation by chemoheterotrophic bacteria or yeasts, or via transesterification. Each of these separate steps has an efficiency that is significantly lower than one, which leads to appreciably lowered overall efficiency. Significantly, in the fermentative sugar catabolism the same C(3) sugars play an intermediate role as those that are the end products of the Calvin cycle. This then makes it possible to propose a shortcut that can considerably reduce the number of conversion processes in biofuel production.

\section{A Photofermentative Chimera}

Hellingwerf and Teixeira de Mattos therefore have proposed the photanol approach (Hellingwerf and Teixeira de Mattos 2009); see also (Angermayr et al. 2009): Lightdriven conversion of $\mathrm{CO}_{2}$ and water into biofuel can be achieved by combining the elementary reactions of photosynthesis and the Calvin cycle in combination with a fermentative pathway from a chemoheterotrophic microorganism in one single chimera (see Fig. 2). In 1999, Deng and Coleman (1999) already provided evidence that ethanol can be formed in this way by Synechococcus sp. strain PCC 7942 after heterologous expression of pyruvate decarboxylase (PDC) and an alcohol dehydrogenase from Zymomonas mobilis. More recently, Dexter and Fu (2009) demonstrated the functionality of the same chimeric type of metabolism in the cyanobacterium Synechocystis sp. PCC 6803 and we have recently shown that this approach can be used to produce additional products (S.A. Angermayr et al., data not shown).

Significantly, the photanol approach is not constrained to ethanol, but rather can be used for a broad range of (fermentation) end products. Any relatively reduced fuel product that can be made from $\mathrm{C}(3)$ sugars, like glyceraldehydes-3-phosphate or pyruvate, in a limited number of metabolic steps, qualifies. For example, products like 2,3-butanediol and butanol are interesting products in this respect because of their superior fuel properties as compared with ethanol and the relatively short (i.e., three to four steps) metabolic routes that are available for their synthesis. However, one can think of many additional products like volatile organic compounds such as ethylene, mono and dicarboxylic acids like lactic and succinic acid, alcohols, ketones, etc. (see further blow).

A key feature of these heterologous fermentation pathways that will have to be introduced into the cyanobacterium is that the enzymes encoded should be able to function in an environment that actively produces oxygen. A significant aspect of the successful development of the photanol concept will therefore be to test (and perhaps increase) the oxygen tolerance of fermentative-pathway enzymes. The latter of these approaches, i.e., the improvement of oxygen tolerance of fermentative enzymes through directed evolution would benefit from dedicated $E$. coli test strains. Such strains are currently being developed in our lab. The inverse approach, i.e., cloning the photosynthesis system into a chemoheterotrophic microorganism (Johnson and Schmidt-Dannert 2008) is much more cumbersome (Itaya et al. 2005).

Synechocystis sp. PCC 6803 is the organism of choice as the host for the heterologous fermentative pathways in the photanol approach. This cyanobacterium is best characterized molecularly. Its sequenced genome (Kaneko et al. 1995 ) is publicly available via Cyanobase (Nakamura et al. 2000) as well as the results of several additional genomewide characterizations (Bohnert et al. 2001; Burja et al. 2003). The organism shows impressive growth characteristics and high-photosynthetic yields. Furthermore, cyanobacteria, being prokaryotes, can be engineered genetically in much simpler ways than eukaryotic algae (Vermaas 1998), and this particular organism is naturally transformable, which allows - via homologous recombinationdirect targeting of heterologous genes into the genome of the recipient organism (Grigorieva and Shestakov 1982). This in turn provides strongly enhanced genetic stability 
Fig. 2 The photanol concept: Various fermentation pathways (i.e., via an $l d h$ to form lactic acid) from a chemotrophic organism (i.e., Lactococcus lactis in case of L-ldh) can be introduced by genetic engineering into a cyanobacterium. Endogenous metabolism will provide the newly introduced enzymes with precursor metabolites (like glyceraldehyde-3-phosphate, NADPH (and ATP) to form desired end products

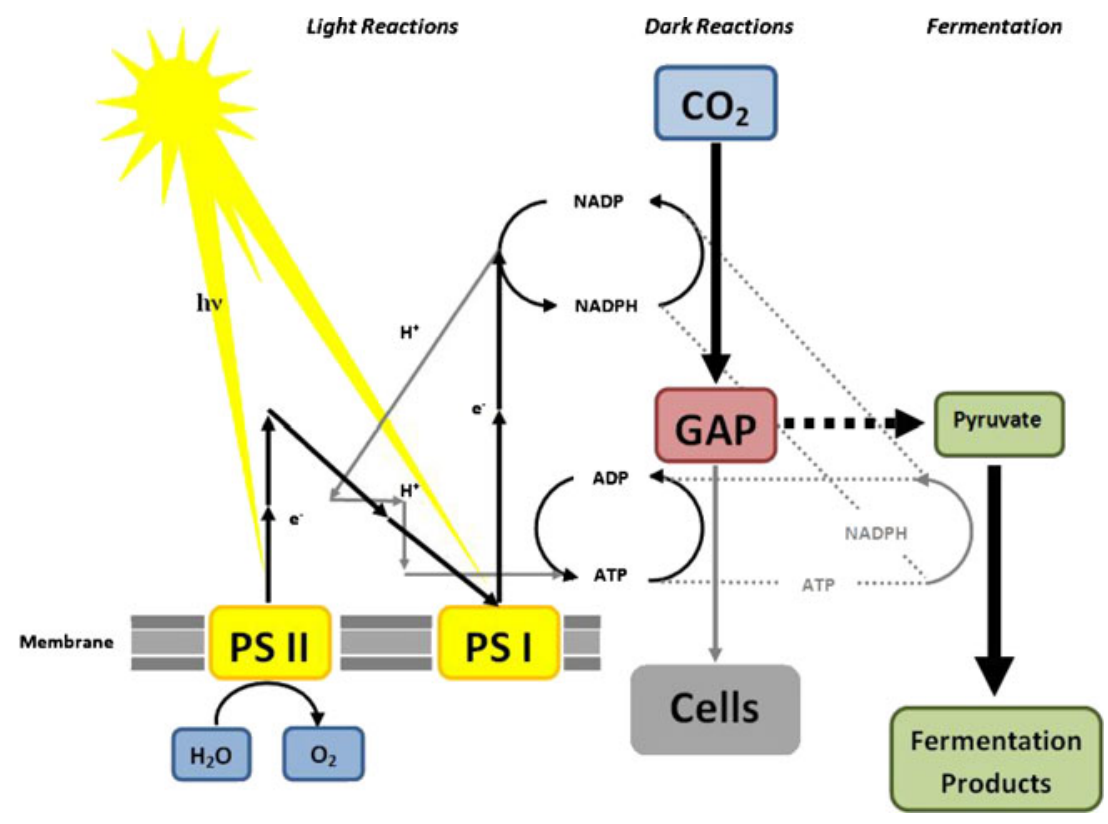

and straightforward ways for gene amplification (Tyo et al. 2009).

Important aspects of the photanol approach that have so far been little addressed are product toxicity and product recovery. With respect to the latter, it will be of great advantage to produce a product in a separate phase, e.g., as a precipitate or in the gas phase. To achieve the latter it will be important to expand studies towards thermophilic phototrophic microorganisms and/or on products with a low boiling point. Examples can already be found in the literature where ethylene, isobutyraldehyde, and isoprene production have been reported in two different types of cyanobacteria (Atsumi et al. 2009; Takahama et al. 2003; Lindberg et al. 2010). The rates of synthesis of these compounds were shown to be either very low (for isobutyraldehyde and isoprene synthesis) or unstable (in the case of ethylene formation by the ethylene-forming enzyme). Possibly products, like acetone, butanol, and propanol can also be synthesized via the photanol approach (see Table 1).

Products like succinic acid cannot be easily purified from solution especially when one takes into account the expected relatively low final product concentrations. High product concentrations generally lead to cellular toxicity and product inhibition. Product toxicity in nature generally is counteracted through the (increased) expression of dedicated efflux systems (Rojas et al. 2001). This approach may also work in cyanobacteria with respect to biofuel molecules, although for these bacteria no specific examples in literature are yet available.

Another aspect that has received little attention is the unavoidable alteration between light and dark in large- scale culturing. A key aspect herein is the type of metabolism that the phototrophic organism uses to survive in the dark. An important factor in this will be the amount of oxygen available in this latter period, which presumably in high-density cultures will be low. This then may lead to fermentative metabolism, which is associated with the formation of organic acids (Stal and Moezelaar 1997). It would be of interest to resolve whether low-intensity red-light illumination could be used as an economically viable tool to suppress this latter type of metabolism.

In the photanol approach one does make use of the enzyme RuBisCo for the fixation of $\mathrm{CO}_{2}$. This enzyme significantly decreases the overall efficiency of photosynthesis below the theoretical maximum through the process of photorespiration ( $\mathrm{Zhu}$ et al. 2008). It is thinkable to also bypass this bottleneck in the photosynthesis process, e.g., through the heterologous overexpression in a cyanobacterium of an enzyme that directly reduces $\mathrm{CO}_{2}$ to another $\mathrm{C}(1)$ compound like formate, e.g., with formate dehydrogenase (Reda et al. 2008). However, enzyme compatibility and enzyme engineering (like introducing ATP-dependence of electron transfer) are important issues to look into before such an approach may become successful.

\section{Feed/Food Applications of Algal Biomass}

On average, algal biomass can be characterized as proteinand/or oil-rich biomass. It therefore is not only an attractive source for biorefinery (see above), but it can also be used 
directly for feed applications; even anecdotal examples of its direct use as food are available (for review see e.g., Spolaore et al. 2006). Important applications in this respect are found in fish farming. Optimization of this process through increased feeding efficiency and use of specific diets is an important issue in this field (Naylor et al. 2000). Increasing the efficiency of the conversion of the feed provided into biomass of the fish implies the need for improvement of farming performances plus a reduction of the amount of biological waste produced by aquaculture ponds. Furthermore, replacement of fishmeal with algae- or plant-derived protein sources will lower the proportion of captured wild fish used as feed component.

Besides changing the source of the feed for aqua-culturing also changing its macromolecular composition may contribute to this waste reduction. Partial substitution of dietary proteins by carbohydrates is for instance tolerated by the carnivorous fish Sparus aurata through adaptation of key enzymes involved in the regulation of the intermediary metabolism in the liver. Alternative splicing of the Sabanejewia aurata cytosolic alanine aminotransferase (cALT) gene generates two transcripts, cALT1 and cALT2, with different metabolic implications: cALT1 is predominant during postprandial utilization of dietary nutrients, whereas cALT2 is mainly involved in gluconeogenesis in the liver (Anemaet et al. 2008). It would be of interest to know whether modulation of the splicing ratio of cALT could further enhance the degree to which $S$. aurata can tolerate substitution of protein by carbohydrate in its daily diet.

In 2004, the worldwide annual production of algal biomass was estimated to be 5,000 t of dry biomass (Pulz and Gross 2004). Approximately one fifth of this biomass has been used to nourish the fish and shellfish that are cultivated in aquaculture hatcheries (Muller-Feuga 2004). In this application algae are an important alternative to fish oil as they mainly consist of protein and fat, the latter being composed for a large part of omega-3 fatty acids. Ganuza et al. (2008) confirmed that the unicellular heterotrophic algae Crypthecodinium cohnii and Schizochytrium sp. can be used to substitute the fish-derived oils in the gilthead seabream (Sparus aurata) microdiets.
Algal Biomass for Fish Farming

Apart from the requirement for microalgae for culturing and/ or enriching live prey organisms such as Artemia and rotifers, algae are also often used directly in tanks for rearing marine fish larvae (see Table 2). The stimulating effects of the presence of microalgae in these rearing tanks are not fully understood. They may include such diverse effects as stabilization of the water quality in static rearing systems (e.g., via removal of metabolic waste products, the production of oxygen, etc.), stimulation of the non-specific immune system of the larvae, indirect delivery of nutrients for the fish larvae through live feed (i.e., by maintaining the nutritional value of the live prey organisms in the tank), an increase in the feeding incidence by enhancing visual contrast and light dispersion, and microbial control via algal exudates in the tank water and/or larval gut (Alabi et al. 1999).

The demand for fish feed will increase as the demand for fish for human consumption rises due to the environmental concerns over open ocean fishing. Therefore, algal biomass will be in high demand for the fish-food and aquaculture markets in the time to come and provide ample revenues for the algae industry.

\section{Algal Biomass for "Vitromeat"}

A sustainable development of society in general may also require drastic changes in human consumption. To give an example: The environmental load of the level of meat consumption in the Western world is such that it will not be maintainable for the entire world population because of its very high energy (e.g., fertilizer) and fresh-water requirement. Therefore, various initiatives are being taken to provide alternatives for this component of the human diet. One of these is often referred to as the "vitromeat" approach and implies the in vitro culturing of cells preferably derived from the muscle of a mammal to form an edible product (Edelman et al. 2005).

Success in this approach heavily depends on finding a suitable cheap growth medium for these mammalian myoblasts. An important component in such media is the
Table 2 Algae currently in use for rearing marine fish larvae

Source: FAO website (http:// www.fao.org/docrep/003/ W3732E/w3732e08.htm).

${ }^{\text {a }}$ For growing $S$. aurata in a 10,000-L tank on Chlorella this implies $1.2 .10^{15}$ cells (with $\sim 10^{-12}$ g per cell), so approximately $1 \mathrm{~kg}$ dry weight per year (see also Maruyama et al. 1997)

\begin{tabular}{lll}
\hline Fish species & Algal species & Amount (cells $\mathrm{mL}^{-1} \mathrm{day}^{-1}$ ) \\
\hline Sparus aurata & Isochrysis & 50,000 \\
& Chlorella & $400,000^{\mathrm{a}}$ \\
Chanos chanos & Chlorella & $500-3,500$ \\
Coryphaena hippurus & Chaetoceros gracilis & 200,000 \\
& Chlorella & 200,000 \\
Hippoglossus hippoglossus & Tetraselmis & 60,000 \\
Scophthalmus maximus & Tetraselmis & 60,000 \\
& Isochrysis galbana & 130,000 \\
\hline
\end{tabular}


source of amino acids. Hydrolysates of plants are already in use to substitute the fetal calf serum (Chun et al. 2005; George et al. 2009). Algal biomass, also because of its high protein content, is an attractive starting point for the development of such medium constituents. Initial results in this approach, obtained in our research group hold great promise for success (M. Daniels et al., unpublished).

\section{Conclusions}

Mass culturing of algae particularly because of the high efficiency with which in this process light energy is converted into biomass, has a bright future as more and more emphasis has to be placed on the sustainability and required surface area of mainstream processes for the supply of energy and food to the human population. An added asset of this approach is that there is no need to compete for arable land in setting up large-scale culturing facilities. One could even go one step further and explore to which extent the marine environment could contribute to the surface area requirements of these mass cultures.

Algal biomass, being rich in protein and valuable fatty acid species, has a favorable composition for various applications. Nevertheless, in selected applications it pays off to fractionate the biomass for the enrichment of a selected component. In all such biorefinery approaches, it is worthwhile to consider whether the available raw material can be further optimized prior to being subjected to the fractionation. Furthermore, it is important to point out that the accessibility to genetic engineering generally is quite good in these microorganisms, particularly in the subgroup of the prokaryotic phototrophs.

Beyond the topics discussed in this review, entirely new applications of oxygenic photosynthesis in prokaryotic and eukaryotic microalgae still remain to be explored. One example is to design and/or grow cyanobacteria that are predominantly composed of polysaccharide to provide optimized substrate for $\mathrm{ABE}$ fermentation. Another is the use of exudate for direct generation of electricity (Strik et al. 2008). These examples plus the remainder of this text, we hope, make it clear that algal photosynthesis has a bright future as the primary driver for a sustainable development in energy, feed and food production.

Open Access This article is distributed under the terms of the Creative Commons Attribution Noncommercial License which permits any noncommercial use, distribution, and reproduction in any medium, provided the original author(s) and source are credited.

\section{References}

Alabi AO, Cob ZC, Jones DA, Latchford JW (1999) Aquac Int 7 (3):137-158
Anemaet IG, Meton I, Salgado MC, Fernandez F, Baanante IV (2008) Int J Biochem Cell Biol 40(12):2833-2844

Angermayr SA, Hellingwerf KJ, Lindblad P, de Mattos MJT (2009) Curr Opin Biotechnol 20(3):257-263

Atsumi S, Cann AF, Connor MR, Shen CR, Smith KM, Brynildsen MP, Chou KJY, Hanai T, Liao JC (2008) Metab Eng 10(6):305311

Atsumi S, Higashide W, Liao JC (2009) Nat Biotechnol 27(12):11771180

Atsumi S, Wu TY, Eckl EM, Hawkins SD, Buelter T, Liao JC (2010) Appl Microbiol Biotechnol 85(3):651-657

Balashov SP, Lanyi JK (2007) Cell Mol Life Sci 64(18):2323-2328

Blankenship RE (2002) Oxford,UK,Blackwell Science

Bohnert HJ, Ayoubi P, Borchert C, Bressan RA, Burnap RL, Cushman JC, Cushman MA, Deyholos M, Fischer R, Galbraith DW, Hasegawa PM, Jenks M, Kawasaki S, Koiwa H, Kore-eda S, Lee BH, Michalowski CB, Misawa E, Nomura M, Ozturk N, Postier B, Prade R, Song CP, Tanaka Y, Wang H, Zhu JK (2001) Plant Physiol Biochem 39(3-4):295-311

Boichenko VA, Greenbaum E, Seibert M (2004) Photoconversion of Solar Energy, molecular to global photosynthesis. Imperial College Press, London

Boyer JS (1982) Science 218(4571):443-448

Bryant DA, Frigaard NU (2006) Trends Microbiol 14(11):488-496

Buerkert A, Schlecht E (2009) J Agric Rural Dev Trop 110(1):1-8

Burja AM, Dhamwichukorn S, Wright PC (2003) Trends Biotechnol 21(11):504-511

Chisti Y (2007) Biotechnol Adv 25(3):294-306

Chisti Y (2008) Trends Biotechnol 26(3):126-131

Chu BC, Lee H (2007) Biotechnol Adv 25(5):425-441

Chun BH, Lee YK, Bang WG, Chung N (2005) Biotechnol Lett 27 (4):243-248

De Vos A, de Mey G (1977) Arch Meteorol Geophys Bioklimatol Ser B 25:135-150

Deng MD, Coleman JR (1999) Appl Environ Microbiol 65(2):523528

Dexter J, Fu P (2009) Energy Environ Sci 2:857-864

Dote Y, Sawayama S, Inoue S, Minowa T, Yokoyama S (1994) Fuel 73:1855-1857

Edelman PD, McFarland DC, Mironov VA, Matheny JG (2005) Tissue Eng 11(5-6):659-662

Elsey D, Jameson D, Raleigh B, Cooney MJ (2007) J Microbiol Methods 68(3):639-642

Etheridge DM, Steele LP, Langenfields RL, Francey RJ, Barnola JM, Morgan VI (1996) J Geophys Res 101:4115-4128

Galbe M, Zacchi G (2007) Adv Biochem Eng Biotechnol 108:41-65

Ganuza E, Benítez-Santana T, Atalah E, Vega-Orellana O, Ganga R, Izquierdo MS (2008) Aquacult 277:109-116

Geng D, Wang Y, Wang P (2003) J Appl Phycol 15:451-456

George F, Kerschen D, Van Nuffel A, Rees JF, Donnay I (2009) Reprod Fertil Dev 21(4):587-598

Geyer T, Helms V (2006) Biophys J 91(3):927-937

Geyer T, Lauck F, Helms V (2007) Biophys J 648a-648a

Ginzburg B (2003) Renewable Energy 3:249-252

Gons HJ, Mur LR (1980) Arch Microbiol 125(1-2):9-17

Gratzel M (2001) Nature 414(6861):338-344

Grigorieva G, Shestakov S (1982) FEMS Microbiol Lett 13:367-370

Hellingwerf KJ, Konings WN (1985) Adv Microb Physiol 26:125154

Hellingwerf KJ, Teixeira de Mattos MJ (2009) J Biotechnol 142 (1):87-90

Hill J, Nelson E, Tilman D, Polasky S, Tiffany D (2006) Proc Natl Acad Sci USA 103(30):11206-11210

Hovatta I, Barlow C (2008) Ann Med 40(2):92-109

Itaya M, Tsuge K, Koizumi M, Fujita K (2005) Proc Natl Acad Sci USA 102(44):15971-15976 
Janssen M, de Bresser L, Baijens T, Tramper J, Mur LR, Snel JFH, Wijffels RH (2000) J Appl Phycol 12(3-5):225-237

Janssen M, Tramper J, Mur LR, Wijffels RH (2003) Biotechnol Bioeng 81(2):193-210

Jimenez C, Cossio BR, Labella D, Niell FX (2003) Aquaculture 217 (1-4):179-190

Johnson ET, Schmidt-Dannert C (2008) Trends Biotechnol 26 (12):682-689

Kaneko T, Tanaka A, Sato S, Kotani H, Sazuka T, Miyajima N, Sugiura M, Tabata S (1995) DNA Res 2(4):153-166, 191-158

Laist DW (1987) Mar Pollut Bull 18(6B):319-326

Langeveld JWA, van de Ven GWJ, de Vries SC, Brink L, de Visser CLM (2008) Ethanol from sugar beet in The Netherlands: energy production and efficiency. In: 8th European IFSA Symposium, Clermont Ferrand

Larcher W (2003) Springer Verlag, Berlin, Germany

Lindberg P, Park S, Melis A (2010) Engineering a platform for photosynthetic isoprene production in cyanobacteria, using Synechosystis as the model organism. Metab Eng 12(1):70-79

Lynd L, Greene N, Dale B, Laser M, Lashof D, Wang M, Wyman C (2006) Science 312(5781):1746-1748, author reply 1746-1748

Mandalam RK, Palsson BO (1998) Biotechnol Bioeng 59(5):605-611

Marris E (2006) Nature 444(7120):670-672

Maruyama I, Nakao T, Shigeno I, Ando Y, Hirayama K (1997) Hydrobiologia 358:133-138

Meehan J (2008) Acetone. In: I Pricing (ed)

Metzger P, Largeau C (2005) Appl Microbiol Biotechnol 66(5):486496

Milne TA, Evans RJ, Nagle N (1990) Biomass 21:219-232

Minowa T, Yokoyama S, Kishimoto M, Okakura T (1995) Fuel $74: 1735-1738$

Mosier N, Wyman C, Dale B, Elander R, Lee YY, Holtzapple M, Ladisch M (2005) Bioresour Technol 96(6):673-686

Muller P, Li XP, Niyogi KK (2001) Plant Physiol 125(4):1558-1566

Muller A, Schmidhuber J, Hoogeveen J, Steduto P (2008) Water Policy 10:83-94

Muller-Feuga A (2004) In: A Richmond (ed) Handbook of Microalgal Culture. Blackwell Science pp. 352-364

Nakamura Y, Kaneko T, Tabata S (2000) Nucleic Acids Res 28(1):72

Naylor RL, Goldburg RJ, Primavera JH, Kautsky N, Beveridge MC, Clay J, Folke C, Lubchenco J, Mooney H, Troell M (2000) Nature 405(6790):1017-1024

Nelson N, Ben-Shem A (2004) Nat Rev Mol Cell Biol 5(12):971-982
Oswald WJ, Gotaas HB, Ludwig HF, Lynch V (1953) Sewage Ind Waste 25:692-705

Papoutsakis ET (2008) Curr Opin Biotechnol 19(5):420-429

Posten C (2009) Eng Life Sci 9(3):165-177

Pulz O, Gross W (2004) Appl Microbiol Biotechnol 65(6):635-648

Ratchford IAJ, Fallowfield HJ (1992) J Appl Phycol 4(1):1-9

Ratledge C (2004) Biochimie 86(11):807-815

Reda T, Plugge CM, Abram NJ, Hirst J (2008) Proc Natl Acad Sci USA 105(31):10654-10658

Rojas A, Duque E, Mosqueda G, Golden G, Hurtado A, Ramos JL, Segura A (2001) J Bacteriol 183(13):3967-3973

Rolim MM, Fraidenraich N, Tiba C (2009) Sol Energy 83(1):126-133

Slater EC (1976) FEBS Lett 64(1):3-5

Smith RP, Larkin GL, Southwick SM (2008) J Clin Psychiatry 69 (2):286-294

Song H, Lee SY (2006) Enzyme Microb Technol 39(3):352-361

Spolaore P, Joannis-Cassan C, Duran E, Isambert A (2006) J Biosci Bioeng 101(2):87-96

Stal LJ, Moezelaar R (1997) FEMS Microbiol Rev 21(2):179-211

Strik DPBTB, Hamelers HVM, Snel JFH, Buisman CJN (2008) Int J Energ Res 32(9):870-876

Takahama K, Matsuoka M, Nagahama K, Ogawa T (2003) J Biosci Bioeng 95(3):302-305

Tan C, Qin S, Zhang Q, Jiang P, Zhao F (2005) J Microbiol 43 (4):361-365

Tempest DW, Neijssel OM (1979) Biochem Soc Trans 7(1):82-85

Thauer RK, Kaster AK, Seedorf H, Buckel W, Hedderich R (2008) Nat Rev Microbiol 6(8):579-591

Tyo KEJ, Ajikumar PK, Stephanopoulos G (2009) Nat Biotechnol 27 (8):760-U115

Usui N, Ikenouchi M (1997) Energy Conv Manag 38:S487-S492

van Dongen M, Bossenbroek J, Piera T (2008) Biobased Economy Exploring opportunities for The Netherlands. In: Leusden

Van Wijk JP (2001) Trends Biotechnol 19:172-177

Vermaas WF (1998) Methods Enzymol 297:293-310

Vetter A (2005)

Viikari L, Alapuranen M, Puranen T, Vehmaanpera J, Siika-Aho M (2007) Adv Biochem Eng Biotechnol 108:121-145

Walker TL, Purton S, Becker DK, Collet C (2005) Plant Cell Rep 24 (11):629-641

Woods DR (1995) Trends Biotechnol 13(7):259-264

Zhu XG, Long SP, Ort DR (2008) Curr Opin Biotechnol 19(2):153159 